\title{
Behavior of Jet from Nozzle Set on Side Wall of Lance
}

\author{
Nobuhiko ODA, ${ }^{1) *}$ Shinji KOSEKI, ${ }^{1)}$ Yu-ichi UCHIDA, ${ }^{2)}$ Yuta HINO ${ }^{1)}$ and Naoki KIKUCHI ${ }^{11}$ \\ 1) Steelmaking Research Dept. Steel Research Laboratory, JFE Steel Corporation, 1 Kawasaki-cho, Chuo-ku, Chiba, 260-0835 \\ Japan. \\ 2) Nippon Institute of Technology, 4-1 Gakuendai, Miyashito-machi, Saitama, 345-8501 Japan. \\ (Received on December 21, 2020; accepted on March 5, 2021; originally published in Tetsu-to-Hagané, \\ Vol. 106, 2020, No. 2, pp. 100-107)
}

\begin{abstract}
In a top-blowing converter, when a distance between the top-blowing lance and the molten metal surface increases, post-combustion ratio increases, but its heat transfer efficiency to the molten metal decreases. Therefore, a fundamental study of a gas jet behavior from the lance nozzles was carried out in order to develop a new oxygen top-blowing lance with side nozzles with the aim of achieving both higher post-combustion ratio and higher heat supply to the molten metal in converter.

In order to design the shape of the side nozzles and blowing conditions, cold model experiments and numerical calculations were carried out to investigate the effect of the inclination angle of the side nozzles and the flow rate on the gas jet behavior of the nozzles. It was found that the gas jet from the side nozzles was deflected to the direction away from the side wall of the lance due to a difference in the pressure distribution at the nozzle outlet. The deflection angle can be estimated by an equation using the supply pressure, atmospheric pressure and inclination angle of the nozzle.
\end{abstract}

KEY WORDS: converter; lance; nozzle; jet; post-combustion; deflection.

\section{Introduction}

In the steelmaking process, it is possible to reduce $\mathrm{CO}_{2}$ emissions by increasing the amount of scrap used. ${ }^{1,2)}$ In order to increase the amount of scrap, heat supply for melting scrap is important. Various oxygen blowing lances which promote post-combustion have been examined as heat supply technology in converter. ${ }^{3-7)}$ However, when the distance between the lance tip and the surface of molten metal is increased, the post-combustion ratio increases, but the heat transfer efficiency to the molten metal decreases. ${ }^{5)}$

On the other hand, a lance having a nozzle for supplying oxygen to the side surface of the lance body in addition to the lance tip has been developed in order to melt the metal adhering to the throat of the converter. ${ }^{8)}$ The lance is designed so that the side holes are perpendicular to the lance insertion direction. Since oxygen from this side hole is burned in the vicinity of converter throat, there is little heat transfer to the molten metal. Therefore, it has been thought that this technology cannot supply heat.

In this study, we discuss a lance that promotes the postcombustion area and enhances the heat transfer efficiency by applying an inclination angle to the molten metal to the side nozzles in order to supply heat through the side nozzles.

In order to develop a lance with side nozzles for post-

\footnotetext{
* Corresponding author: E-mail: no-oda@jfe-steel.co.jp
}

combustion, it is necessary to design the nozzle diameter and inclination angle of the side nozzles, and to determine the conditions of flow rate and pressure of the gas supplied from the side nozzles. These designs are important from the viewpoints of the compatibility of post-combustion rate and heat transfer efficiency, the prevention of direct blowing to converter body and avoiding coalescence of jets from the side holes and jets for refining. Then, we investigated by cold model experiment and numerical calculations, the effect of nozzle inclination angle and gas flow rate and supply pressure on the deflection behavior of the jet from the single nozzle installed on the lance side.

\section{Jet Behavior from Side Hole in Cold Model Experi- ment}

\subsection{Experimental Methods}

Figure 1 shows a schematic diagram of the cold model experiment. A nozzle with an inner diameter of $1.7 \mathrm{~mm}$ was installed inclining inside the half-split pipe and nitrogen gas was supplied from the nozzle. The experimental conditions are shown in Table 1. The Reynolds number was calculated from the mass flow rate and the viscosity at room temperature using the inner diameter of the nozzle as the characteristic length. The inclination angle ( $\theta$ in Fig. 1) of the nozzle was the inclination from the lance central axis similar to the usual nozzle, and it was changed from $45^{\circ}$ to 


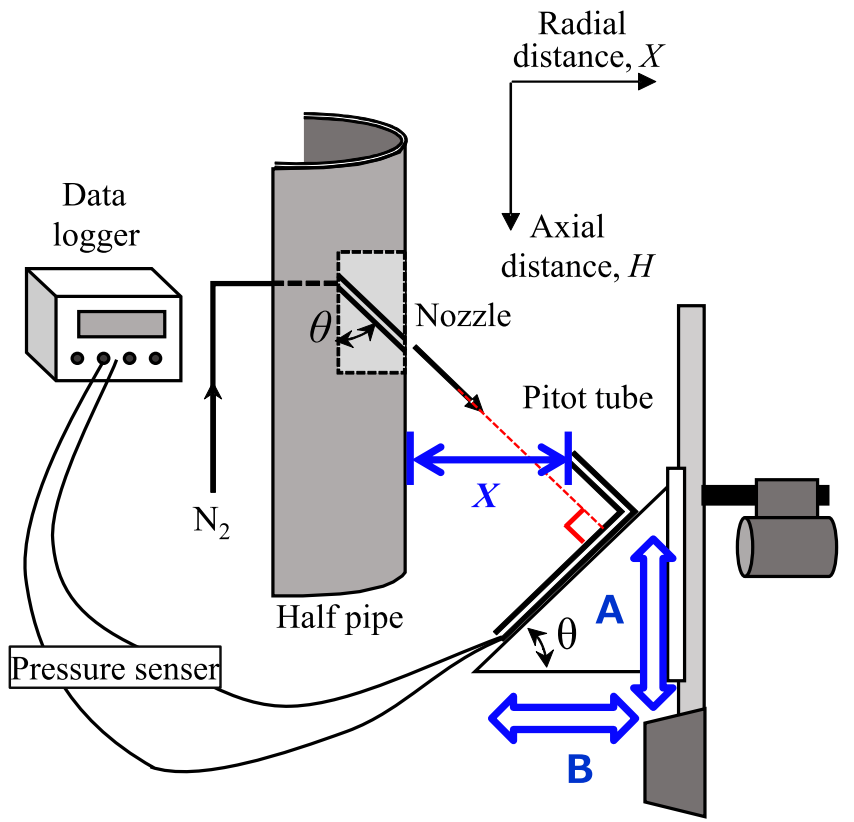

Fig. 1. Schematic diagram of cold model experiments. (Online version in color.)

Table 1. Experimental conditions.

\begin{tabular}{cc}
\hline Diameter of side holes & $1.7 \mathrm{~mm}$ \\
Model gas & $\mathrm{N}_{2}$ \\
Flow rate & $0.10-0.20 \mathrm{Nm}^{3} / \mathrm{min}$ \\
Inclination angle, $\theta$ & $45-90^{\circ}$ \\
Distance from nozzle exit, $X$ & $0-700 \mathrm{~mm}$ \\
Reynolds number, $R e$ & $1 \times 10^{5} \sim 2 \times 10^{5}$ \\
\hline
\end{tabular}

$90^{\circ}$. The inclination angle of the nozzle was set to the angle of the Pitot tube. The distance from the pipe to the tip of the Pitot tube (X in Fig. 1) was kept 20, 50 and $100 \mathrm{~mm}$ and the jet velocity was measured in the direction parallel to the half pipe ( $\mathrm{H}$ in Fig. 1). For example, in the condition of $\mathrm{X}=20 \mathrm{~mm}, \mathrm{~A}$ in Fig. 1 were adjusted in order to conduct the measurement in the $\mathrm{H}$ direction while keeping $\mathrm{X}=20$ mm constant.

\subsection{Experimental Results}

Figure 2 shows the velocity distribution in the case that a flow rate was set to $0.2 \mathrm{Nm}^{3} / \mathrm{min}$ and a inclination angle was $45^{\circ}$. The horizontal axis is the velocity and the vertical axis is the distance in the $\mathrm{H}$ direction. These three velocity distributions show velocity distributions in the case of (a) 20, (b) 50, and (c) $100 \mathrm{~mm}$ in the $\mathrm{X}$-axis direction. The maximum flow velocity decreased as the distance from the nozzle to the $\mathrm{X}$-axis direction increased, and the position of the maximum flow velocity shifted to the direction in which $\mathrm{H}$ increased. The maximum velocity position in each $\mathrm{X}$ coordinate is shown in Fig. 3. When the distance from the side of the pipe is $700 \mathrm{~mm}$ or less, the jet is blown linearly. This inclination is defined as the blown angle $\theta^{\prime}$ of the jet. Figure 3 shows the jet behavior at the inclination angle of $45^{\circ}$. The blown angle $\theta^{\prime}$ of the jet was larger than the inclination angle $\theta$, and the jet was deflected away from the pipe.

Figure 4 shows the deflection angle, $\Delta \theta$, which is defined

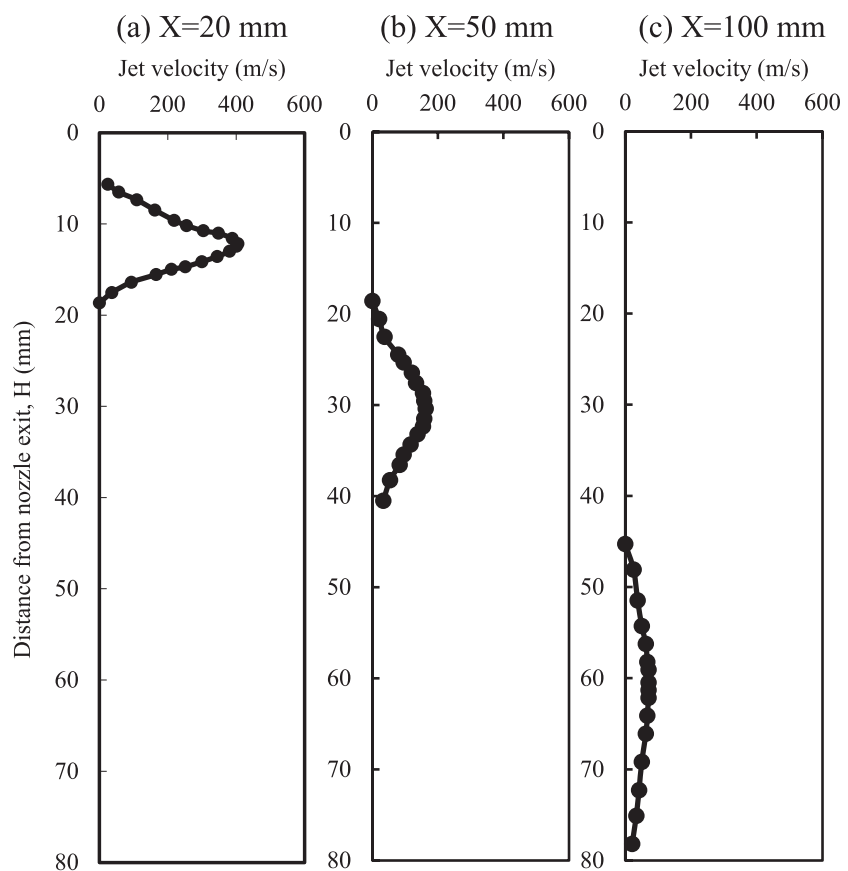

Fig. 2. Examples of velocity distribution of jet (Flow rate 0.2 $\mathrm{Nm}^{3} / \mathrm{min}$, (a) $\mathrm{X}=20 \mathrm{~mm}$, (b) $\mathrm{X}=50 \mathrm{~mm}$, and (c) $\mathrm{X}=100$ $\mathrm{mm})$.

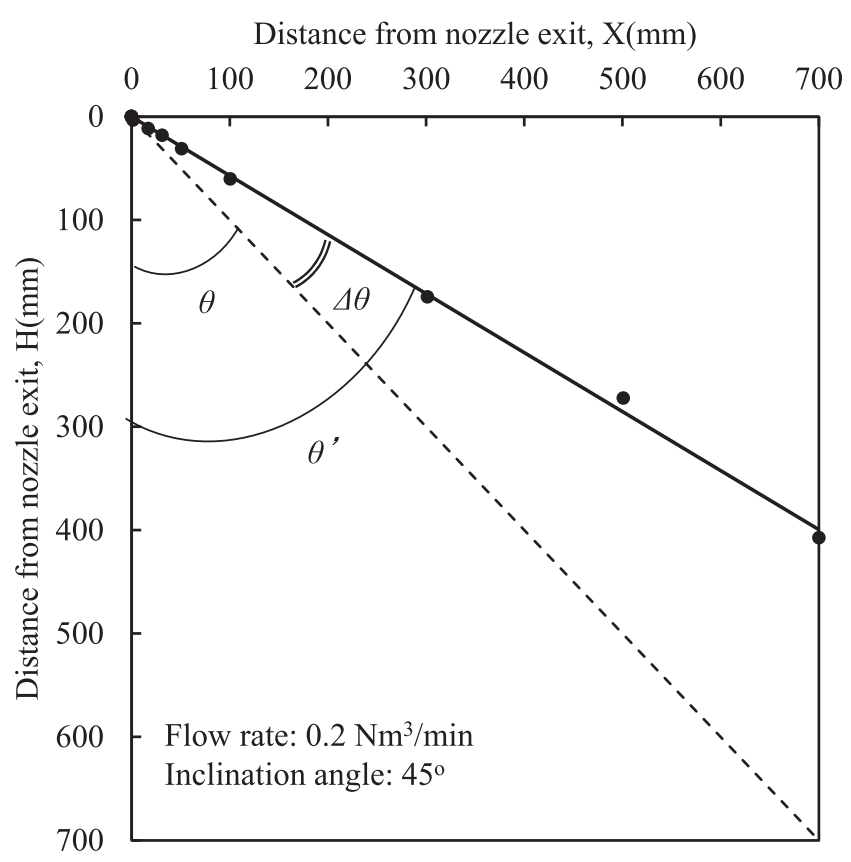

Fig. 3. Measurement of deflection angle.

as the difference between the nozzle inclination angle $\theta$ and the blown angle $\theta^{\prime}$ at the flow rate of $0.2 \mathrm{Nm}^{3} / \mathrm{min}$. Under the condition that the nozzle direction is perpendicular to the pipe and the inclination angle is $90^{\circ}$, the jet did not deflect, and the deflection angle increased as the inclination angle decreased. Figure 5 shows the deflection angle when the inclination angle is set to $45^{\circ}$ and the flow rate is changed. When the nozzle inclination angle was constant, the deflection angle increased as the flow rate increased. 

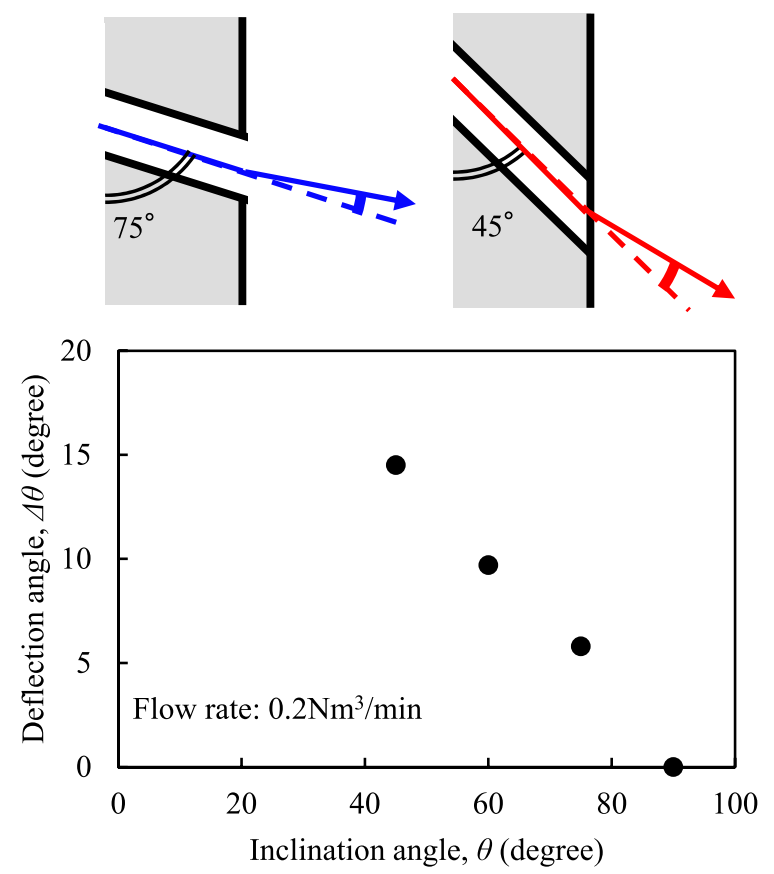

Fig. 4. Relationship between inclination angle and deflection angle. (Online version in color.)
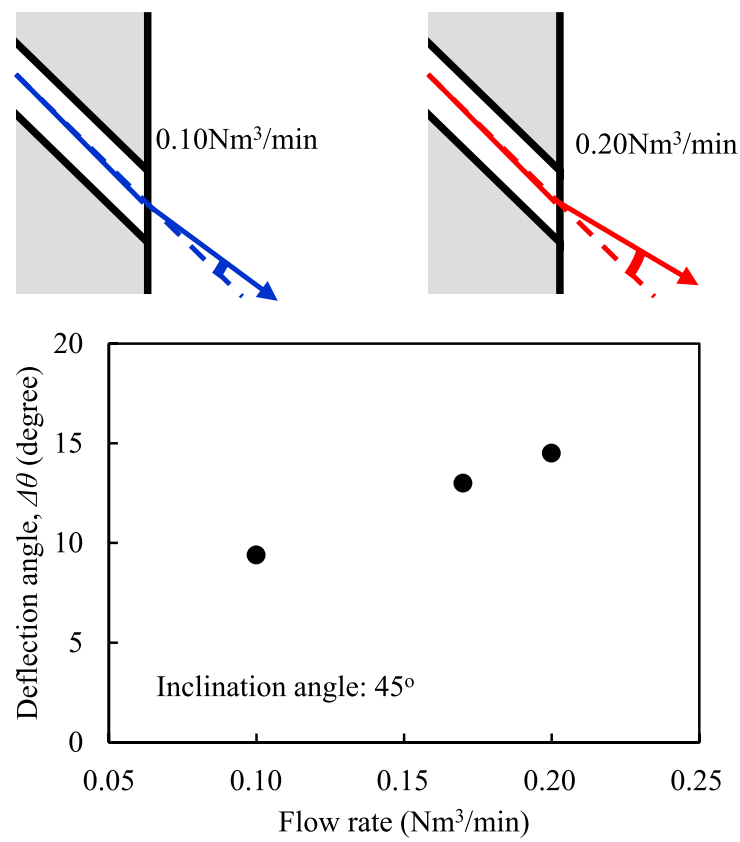

Fig. 5. Relationship between flow rate and deflection angle. (Online version in color.)

\section{Numerical Calculations on the Jet Deflection Behav- ior from Asymmetric Nozzle}

The deflection of the jet from the side nozzles is consistent with the report of Kojima et al. that the underexpanded jet blown from the asymmetric nozzle of which the tip was cut off deflected. ${ }^{9)}$ The results also agree with the tendencies that as the shape of the nozzle tip became acute, and as the supply pressure of the gas increased, that is, as the flow rate increased, the deflection angle increased. That is, the deflection behavior of the jet blown from the side nozzle is determined by the shape of the nozzle tip. In order to evaluate this deflection behavior quantitatively, numerical calculations were carried out.

\subsection{Analysis Conditions}

Numerical calculations of the velocity and pressure distribution in the jets blown from the asymmetric nozzles were carried out by STAR-CCM + ver. 11.04. The governing equations were the compressible Navier-Stokes equation, the continuity equation, the energy conservation equation and the equation of state of the ideal gas, and the turbulence model was the Realizable k- $\varepsilon$ model. Figure 6 shows the analysis area for numerical calculations. The number of analytical grids was about 1 million, and a polyhedral mesh was

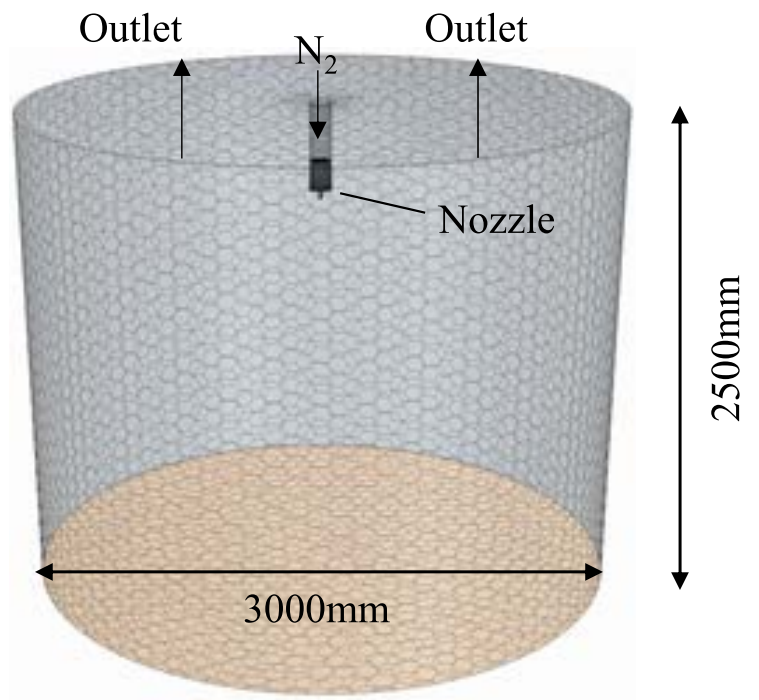

Fig. 6. Schematic diagram of simulation model. (Online version in color.)
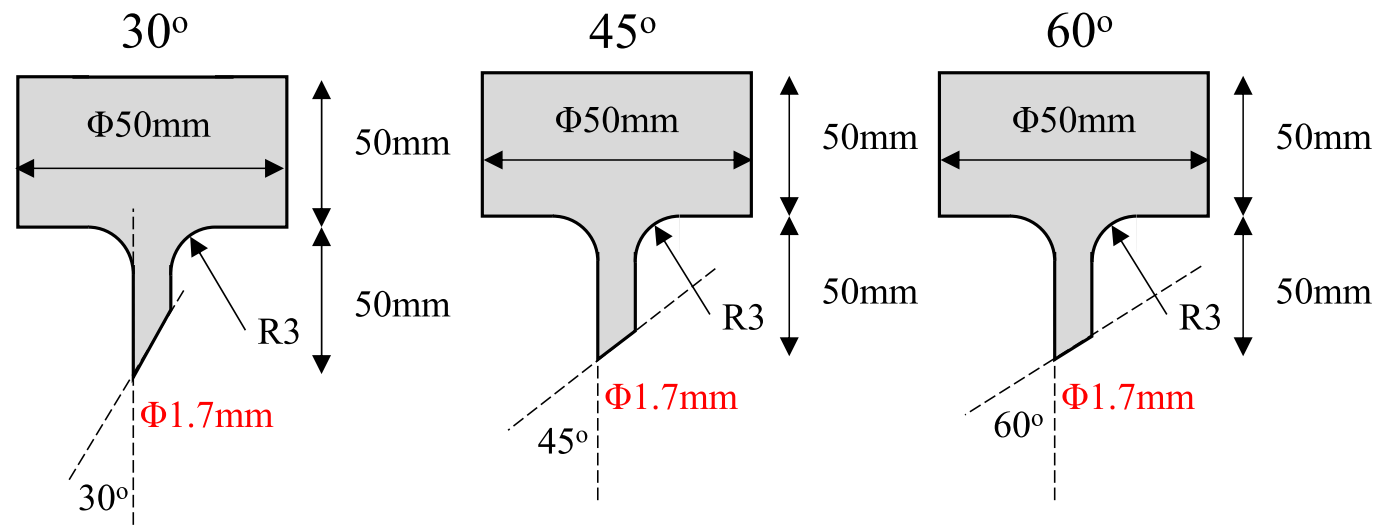

Fig. 7. Shapes of nozzles used in numerical calculations. (Online version in color.) 
used. Here, in order to simplify the analysis at the nozzle tip, the part of the lance body was excluded as shown in Fig. 7, and only the nozzle tip was considered for the analysis. The walls constituting the bottom, side wall and nozzle were no-slip condition. The upper surface inside the nozzle was subjected to inflow at a uniform flow rate, and the pressure at the ceiling was subjected to atmospheric pressure. The temperature of the inflow gas from the upper surface and the ceiling of the nozzle was set to $300 \mathrm{~K}$. Table 2 shows the calculated conditions and calculated gas supply pressure $\mathrm{P}_{\mathrm{o}}$. The gas supply pressure was almost the same under the same flow rate condition. Since the gas supply pressure is determined by the gas flow rate and the area of the minimum cross sectional area of the nozzle, it is considered that under the condition that the nozzle diameter is the same, the gas supply pressure is not affected by the shape of the nozzle tip, and is determined uniquely for the gas flow rate.

\subsection{Numerical Calculation Results}

Figure 8 shows the examples of the numerical calculation results. The left figure shows the deflection behavior when the flow rate was changed at the inclination angle of $45^{\circ}$, and the right figure shows the deflection behavior when the inclination angle was changed from $30^{\circ}$ to $60^{\circ}$

Table 2. Conditions of numerical calculations and calculated supply pressure.

\begin{tabular}{ccc}
\hline \multicolumn{2}{c}{ Conditions of numerical calculations } & Supply pressure, $\mathrm{P}_{\mathrm{o}}$ \\
$\begin{array}{c}\text { Inclination angle, } \theta \\
(\text { degree })\end{array}$ & $\begin{array}{c}\text { Flow rate } \\
\left(\mathrm{Nm}^{3} / \mathrm{min}\right)\end{array}$ & \\
\hline \multirow{3}{*}{30} & 0.10 & $3.9 \times 10^{5}$ \\
& 0.15 & $6.2 \times 10^{5}$ \\
& 0.20 & $8.6 \times 10^{5}$ \\
\hline \multirow{2}{*}{45} & 0.10 & $3.9 \times 10^{5}$ \\
& 0.15 & $6.3 \times 10^{5}$ \\
& 0.20 & $8.6 \times 10^{5}$ \\
\hline \multirow{2}{*}{60} & 0.10 & $3.9 \times 10^{5}$ \\
& 0.15 & $6.3 \times 10^{5}$ \\
& 0.20 & $8.6 \times 10^{5}$ \\
\hline
\end{tabular}

under the condition of $0.2 \mathrm{Nm}^{3} / \mathrm{min}$. The position of the tip of the nozzle is indicated by a broken line. As in the cold model experiment, the jet was blown linearly and deflected from the nozzle installation direction. When the flow rate was increased, the deflection angle increased, and when the inclination angle was decreased, the deflection angle increased. These results agreed with those in the cold model experiment.

Table 3 and Fig. 9 show the relationship between the deflection angle obtained in the cold model experiment $\Delta \theta_{\text {obs }}$ and in the numerical calculation $\Delta \theta_{\text {calc. The deflection }}$ angles in the numerical calculation were smaller than those obtained in the cold model experiment. This overestimation

Table 3. Relationship between numerical calculations and experimental results.

\begin{tabular}{cccc}
\hline $\begin{array}{c}\text { Flow rate } \\
\left(\mathrm{Nm}^{3} / \mathrm{min}\right)\end{array}$ & $\begin{array}{c}\text { Inclination angle, } \theta \\
(\text { degree })\end{array}$ & $\begin{array}{c}\Delta \theta_{\text {obs. }} \\
(\text { degree })\end{array}$ & $\begin{array}{c}\Delta \theta_{\text {calc. }} \\
(\text { degree })\end{array}$ \\
\hline 0.10 & 45 & 9.4 & 6.5 \\
0.17 & 45 & 13 & 11.5 \\
0.20 & 45 & 14.5 & 12.4 \\
0.20 & 60 & 9.7 & 9.1 \\
\hline
\end{tabular}

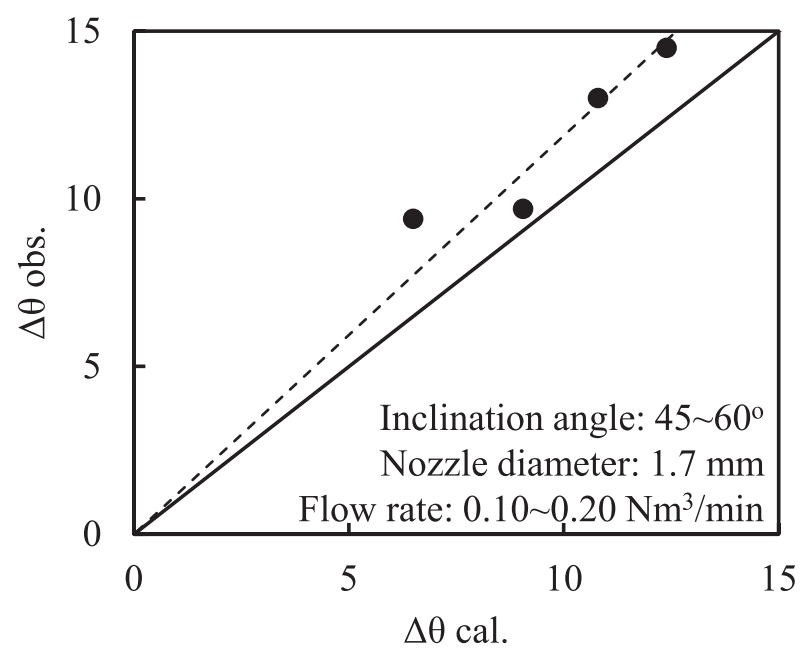

Fig. 9. Relationship between numerical calculations and experimental results.
Inclination angle: $45^{\circ}$

$0.10 \mathrm{Nm}^{3} / \min \quad 0.15 \mathrm{Nm}^{3} / \min \quad 0.20 \mathrm{Nm}^{3} / \mathrm{min}$

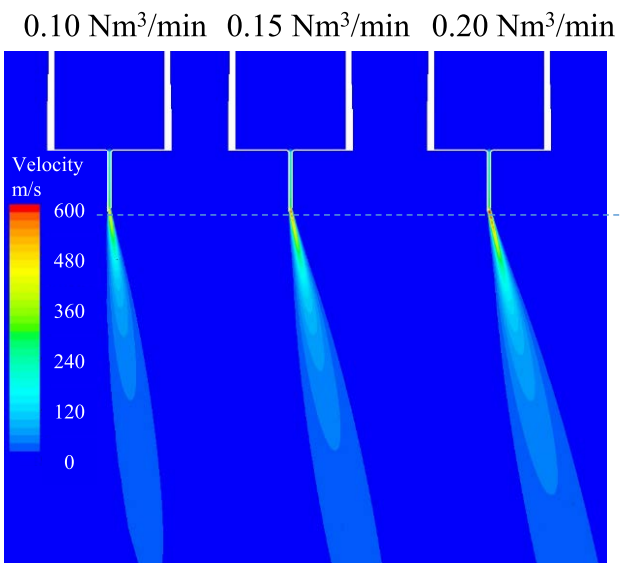

Flow rate: $0.20 \mathrm{Nm}^{3} / \mathrm{min}$

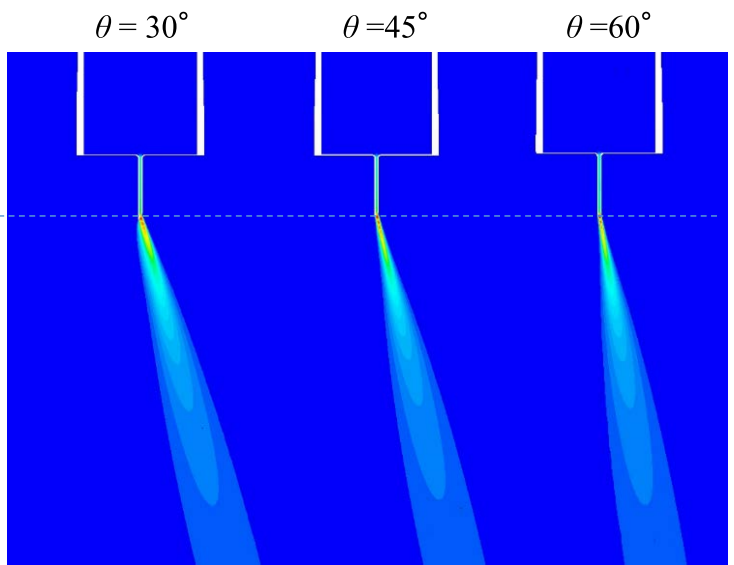

Fig. 8. Results of numerical calculations. (Online version in color.) 
of the deflection angle was caused by the fact that the point at which the jet velocity was the maximum value was the upstream side of the jet, because the scanning direction of the Pitot tube in the flow velocity distribution measurement was not perpendicular to the nozzle axis. This overestimation of the deflection angle was caused by the possibility that the point where the maximum jet velocity obtained was the upstream side of the jet, because the scanning direction of the Pitot tube in the jet velocity distribution measurement was not exactly perpendicular to the nozzle axis. However, the obtained deflection angles are almost the same, and the results of the numerical calculations seem to agree with the results of the cold model experiment. Therefore, it is indicated that the jet deflection from the nozzle installed on the wall surface is caused by the tip shape.

\section{Discussion}

\subsection{Velocity Distribution in the $\mathrm{X}$-Axis Direction at the Nozzle Exit}

Deflection behavior, which depends on the shape of the nozzle tip, was investigated from the viewpoint of changes in static pressure and velocity near the nozzle exit. Figure 10 shows the distribution of static pressure near the nozzle exit and the distribution of $\mathrm{X}$-axis velocity (right side in the figure) and in the $\mathrm{Y}$-axis direction (downward direction in the figure) at the cut-off angle of $45^{\circ}$ and the flow rate of $0.20 \mathrm{Nm}^{3} / \mathrm{min}$. The velocity vector diagram in the same cross-section is also shown. Generally, when the gas is supplied to the straight nozzle at a pressure higher than the critical pressure, the velocity at the nozzle exit is sonic velocity and the static pressure near the exit is higher than the atmospheric pressure. Here, when the specific heat ratio $\gamma=1.4$, the critical pressure ratio is 0.528 , and this condition is satisfied when the gas supply pressure is over $1.9 \times 10^{5} \mathrm{~Pa}$. As shown in Table 2, all of these conditions are satisfied, and the gas is discharged at sonic velocity. Thereafter, as the gas advances in the discharge direction, the static pressure of the gas decreases, and the pressure decrease is converted into the momentum of the jet. As shown in Fig. 10, in the case of the asymmetric nozzle tip, the static pressure distribution in the section $\mathrm{A}$ is uniformly higher than the atmospheric pressure. The static pressure in the section $\mathrm{C}$, which is the tip of the nozzle, decreased to the value close to the external pressure. In the section $B$ at the center of the cut-off part, the static pressure decreases first in the positive range of $\mathrm{X}$ where the nozzle wall surface is short, and then decreased to the atmospheric pressure. The $\mathrm{Y}$-axis velocity increased uniformly in all regions from the section $\mathrm{A}$ to the section $\mathrm{C}$, while the $\mathrm{X}$-axis velocity gradually accelerates from the positive range of $\mathrm{X}$. As a result, as shown in the vector diagram, the jet blown in the $\mathrm{Y}$-axis direction in the section A was gradually deflected from the positive range of $\mathrm{X}$, and finally deflected unidirectionally on the downstream side from the section $\mathrm{C}$.

Figure 11(a) shows the distribution of static pressure in the cross sections A, B and C in Figs. 10, and (b) and (c) show the distribution of $\mathrm{X}$-axis velocity and $\mathrm{Y}$-axis velocity in the cross sections A, B and C, respectively. As previously mentioned, the static pressure distribution was a uniform rectangular distribution of approx.0.25 $\mathrm{MPa}$ in the section $\mathrm{A}$ and the value is close to atmospheric pressure in the section $\mathrm{C}$. In the section $\mathrm{B}$, the static pressure decreased first at the region where $\mathrm{X}$ is positive. In the section $\mathrm{A}$, the $\mathrm{X}$-axis velocity was small, and the jet was blown in the $\mathrm{Y}$-axis direction. In the section $\mathrm{B}$, the $\mathrm{X}$-axis velocity increased at the end of the nozzle exit. This velocity increase position was same as the position where the static pressure difference was the largest in the section A. The velocity distribution in the $\mathrm{X}$-axis direction in the section $\mathrm{C}$ also increased in the nozzle center, and this velocity increase position was the same as the position where the static pressure difference was largest in the section B. From these results, it is indicated that the velocity in the positive direction of the $\mathrm{X}$ axis was generated because the static pressure difference in the $\mathrm{X}$-axis direction near the nozzle exit was converted into the momentum of the gas in the $\mathrm{X}$-axis direction. As a result, the jet was deflected. The velocity distribution in the Y-axis direction was rectangular and the static pressure distribution in the Y-axis direction did not significantly affect the velocity distribution in the $\mathrm{Y}$-axis direction.

\subsection{Quantification of Jet Deflection Behavior}

The deflection angle of the jet depends on the static pressure distribution in the $\mathrm{X}$-axis direction near the nozzle. As shown in Fig. 12, it is assumed that the jet blown in the $\mathrm{Y}$-axis direction at the sonic velocity receives an impulse proportional to the difference between the static pressure $\mathrm{P}_{\mathrm{e}}[\mathrm{Pa}]$ and the atmospheric pressure $\mathrm{P}_{\mathrm{a}}[\mathrm{Pa}]$ from the wall surface while passing through the cut-off part. Focusing on the momentum balance of the gas in the cut-off part at the tip of the nozzle, as shown in Eq. (1), the momentum $p_{y}$ (a) Static pressure

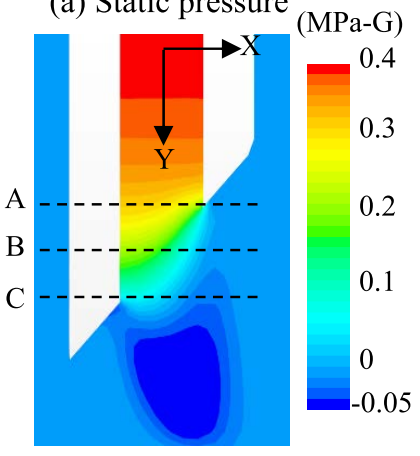

(b) $\mathrm{X}$-axis velocity, $V x$

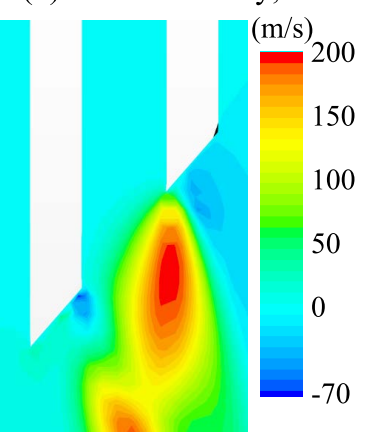

(c) Y-axis velocity, $V y$

(d) Velocity vector diagram

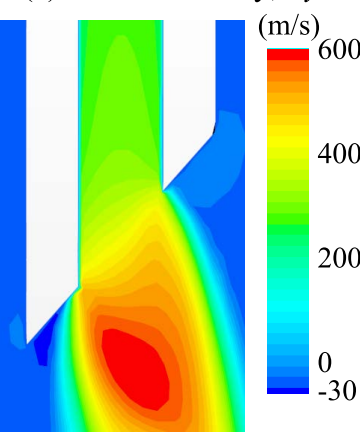

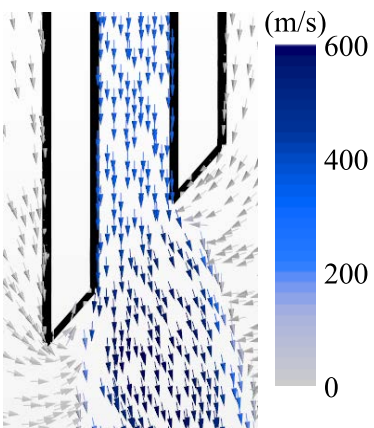

Fig. 10. Contours of static pressure and velocity and a velocity vector diagram. (Online version in color.) 

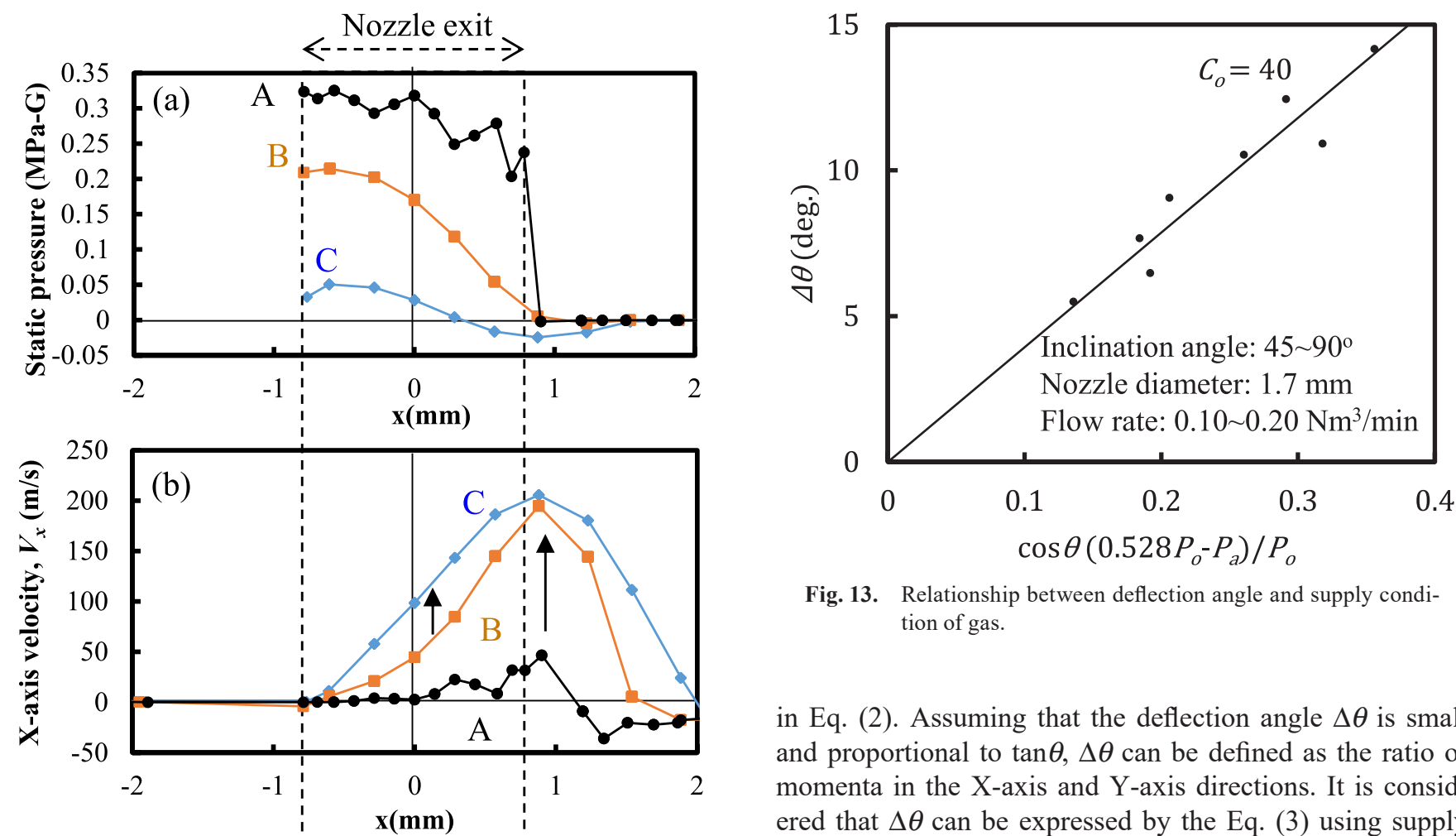

Fig. 13. Relationship between deflection angle and supply condition of gas.

in Eq. (2). Assuming that the deflection angle $\Delta \theta$ is small and proportional to $\tan \theta, \Delta \theta$ can be defined as the ratio of momenta in the $\mathrm{X}$-axis and $\mathrm{Y}$-axis directions. It is considered that $\Delta \theta$ can be expressed by the Eq. (3) using supply pressure $\mathrm{P}_{o}[\mathrm{~Pa}]$, specific heat ratio $\gamma[-]$ and parameter $\mathrm{C}[-]$. When the specific heat ratio $\gamma$ is $1.4, \Delta \theta$ is expressed by the Eq. (4) by using parameter $\mathrm{C}_{0}$. It is also assumed that the gas is in the critical state at the exit of the straight nozzle, the equations was transformed using the Eq. (5) expressing the sonic velocity of the ideal gas, the equation of state (6) and the Eq. (7) expressing the ratio of the pressure in the critical state to the gas supply pressure. Where $\mathrm{R}$ is the gas constant $[\mathrm{J} / \mathrm{kg} \cdot \mathrm{K}]$ and $\mathrm{T}_{\mathrm{e}}$ is the gas temperature $[\mathrm{K}]$ at the nozzle exit.

$$
p_{y}=\rho_{e} \times \frac{\pi}{8} d^{3} \cos \theta \times V_{y}
$$

Fig. 11. Distributions of (a) static pressure, (b) X-axis velocity and (c) Y-axis velocity. (Online version in color.)

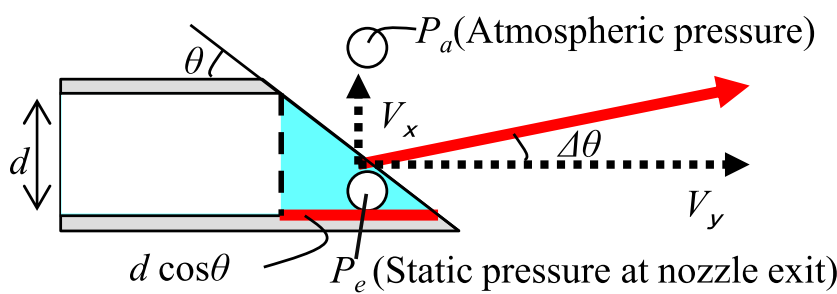

Fig. 12. Mechanism of change of momentum at edge of nozzles. (Online version in color.)

$[\mathrm{kg} \cdot \mathrm{m} / \mathrm{s}]$ in the $\mathrm{Y}$-axis direction is expressed by the product of the gas density $\rho_{\mathrm{e}}\left[\mathrm{kg} / \mathrm{m}^{3}\right]$, the volume and the blown velocity $V_{y}[\mathrm{~m} / \mathrm{s}]$, that is, the sonic velocity. Where, $d[\mathrm{~m}]$ is the nozzle diameter, and the volume of the cut-off cylinder shown in the figure is expressed by $(\pi / 8) \mathrm{d}^{3} \cos \theta$. Next, the momentum in the $\mathrm{X}$-axis direction, which is the deflection direction, is equal to the impulse I $[\mathrm{kg} \cdot \mathrm{m} / \mathrm{s}]$ received from the nozzle wall surface, and is expressed by the product of the pressure difference $\mathrm{P}_{\mathrm{e}}-\mathrm{P}_{\mathrm{a}}[\mathrm{Pa}]$ at the time of discharge, the wall surface area, the time $\Delta \mathrm{t}[\mathrm{s}]$ required to pass through the cut-off portion and the constant parameter $\mathrm{C}$, as shown

$$
\begin{aligned}
& p_{x}=I=C\left(P_{e}-P_{a}\right) \times d^{2} \cos \theta \times \Delta t \\
& =C\left(P_{e}-P_{a}\right) \times d^{2} \cos \theta \times \frac{d \cos \theta}{V_{y}} \\
& \Delta \theta \fallingdotseq \frac{180}{\pi} \tan \theta=\frac{180}{\pi} \frac{p_{x}}{p_{y}} \\
& =\frac{1440 \times C\left(\left(\frac{2}{\gamma+1}\right)^{\frac{\gamma}{\gamma-1}} P_{o}-P_{a}\right) \times \cos \theta}{\pi^{2} \gamma\left(\frac{2}{\gamma+1}\right)^{\frac{\gamma}{\gamma-1}} P_{o}} \\
& \Delta \theta \fallingdotseq C_{o} \cos \theta \times \frac{0.528 P_{o}-P_{a}}{P_{o}} \\
& V y=\sqrt{\gamma \mathrm{R} T_{e}} \\
& P_{e}=\rho_{e} \mathrm{R} T_{e} \\
& \frac{P_{e}}{P_{o}}=\left(\frac{2}{\gamma+1}\right)^{\frac{\gamma}{(\gamma-1)}}
\end{aligned}
$$


Figure 13 shows relationship between deflection angle $\Delta \theta$ obtained from the numerical analysis on the horizontal axis and parameters after $\mathrm{C}_{\mathrm{o}}$ on the right side of Eq. (4). It can be expressed as a straight line, and the deflection angle $\Delta \theta$ can be expressed by the inclination angle $\theta$ and the gas supply pressure $\mathrm{P}_{\mathrm{o}}[\mathrm{Pa}]$. As shown in Eqs. (3) and (4), the fitting parameter of $\mathrm{C}_{\mathrm{o}}$ is only C. In Eq. (2), C is used to indicate the impulsive force applied from the cylinder wall surface to the fluid, so $\mathrm{C}$ is considered to be a parameter depending on the shape of the fluid and the wall surface. Therefore, the same $\mathrm{C}_{0}$ can be used in the case of using the gas having the specific heat ratio of 1.4 in the cut-off nozzles.

From the above result, the deflection angle of the jet blown from the nozzle single hole installed on the nozzle wall surface can be estimated. It is necessary to examine in detail, when the arrangement of the nozzles are designed, considering the effect of interference ${ }^{11)}$ between jet from the side of the lance and the jet for refining installed in the lance tip. In addition, the distance between the nozzles and the metal surface is also important for efficient transfer of the post-combustion heat.

\section{Conclusion}

The behavior of jets discharged from a nozzle installed on the wall surface of a converter top-blown lance was investigated by cold model experiments and numerical analyses. The findings are shown below.

(1) The jet blown from the nozzle installed on the lance side wall was affected by the shape of the nozzle tip, and deflected in the direction away from the lance side wall. The larger the flow rate and the smaller the inclination angle, the larger the deflection angle.

(2) The behavior of the jet blown from the asymmetric nozzle was investigated by numerical calculations. The jet was deflected to the same direction as the cold model experiment. As in the cold model experiment, the larger the flow rate and the smaller the inclination angle, the larger the deflection angle. The deflection angle was almost the same as that in the cold model experiment, and it was indicated that the deflection of the jet from the nozzle installed on the nozzle wall was caused by the nozzle tip shape.

(3) In order to evaluate the deflection angle of the jet, the momentum change near the nozzle exit was estimated based on the assumption that the jet blown from the nozzle receives the impulse proportional to the difference between the static pressure and the atmospheric pressure, and the following experimental equation was obtained using the inclination angle $\theta$ and the supply pressure Po.

$$
\Delta \theta=\frac{1440 \times 0.20\left(\left(\frac{2}{\gamma+1}\right)^{\frac{\gamma}{\gamma-1}} P_{o}-P_{a}\right) \times \cos \theta}{\pi^{2} \gamma\left(\frac{2}{\gamma+1}\right)^{\frac{\gamma}{\gamma-1}} P_{o}}
$$

$\mathrm{d}$ : Nozzle diameter $(\mathrm{m})$

$\theta$ : Inclination angle (degree)

$\theta^{\prime}$ : Blown angle of the jet (degree)

$\Delta \theta$ : Deflection angle of the jet (degree)

$\mathrm{p}_{\mathrm{x}}$ : Momentum of the jet in the $\mathrm{X}$-axis direction $(\mathrm{kg} \cdot \mathrm{m} / \mathrm{s})$

$\mathrm{p}_{\mathrm{y}}$ : Momentum of the jet in the $\mathrm{Y}$-axis direction $(\mathrm{kg} \cdot \mathrm{m} / \mathrm{s})$

I: Impulse $(\mathrm{kg} \cdot \mathrm{m} / \mathrm{s})$ in $\mathrm{X}$-axis direction that the jet receives from the wall surface

$\mathrm{V}_{\mathrm{x}}$ : Velocity of the jet in the $\mathrm{X}$-axis direction $(\mathrm{m} / \mathrm{s})$.

$\mathrm{V}_{\mathrm{y}}$ : Velocity of the jet in the $\mathrm{Y}$-axis direction $(\mathrm{m} / \mathrm{s})$;

$\rho_{\mathrm{e}}$ : Gas density at nozzle exit $\left(\mathrm{kg} / \mathrm{m}^{3}\right)$

$\mathrm{P}_{\mathrm{o}}$ : Gas supply pressure $(\mathrm{Pa})$

$\mathrm{P}_{\mathrm{e}}$ : Static pressure of the gas at nozzle exit $(\mathrm{Pa})$

$\mathrm{P}_{\mathrm{a}}$ : Atmospheric pressure $(\mathrm{Pa})$

$\mathrm{T}_{\mathrm{e}}$ : Gas temperature at nozzle exit $(\mathrm{K})$

$\mathrm{R}$ : Gas constant $(\mathrm{J} / \mathrm{kg} \cdot \mathrm{K})$

$\Delta \mathrm{t}$ : Time to pass through the nozzle (s)

\section{REFERENCES}

1) K. Kamei, H. Shima, N. Matsumoto, A. Minami, A. Nobumoto, K. Oonuki and K. Umezawa: CAMP-ISIJ, 7 (1994), 28 (in Japanese).

2) Y. Ikeda, K. Sakurai, H. Yamauchi, M. Miwa and H. Kobayashi: CAMP-ISIJ, 13 (2000), 772 (in Japanese).

3) M. Hirai, R. Tsujino, T. Mukai, T. Harada and M. Omori: Tetsu-toHagané, 73 (1987), 1117 (in Japanese).

4) N. Takashiba, M. Nira, S. Kojima, H. Take and F. Yoshikawa: Tetsuto-Hagané, 75 (1989), 89 (in Japanese).

5) Y. Kato, J. Grosjean, J. Reboul and P. Riboud: Tetsu-to-Hagané, 75 (1989), 478 (in Japanese).

6) M. Mabuchi, H. Kokubu, H. Nakato and T. Nozaki: Tetsu-to-Hagané, 75 (1989), 1139 (in Japanese).

7) S. Nishioka, H. Nakamura, K. Takahashi, Y. Kawai and S. Sugiyama: Tetsu-to-Hagané, 76 (1990), 2019 (in Japanese).

8) T. Sera and K. Hinode: NKK Giho, 175 (2001), 50 (in Japanese)

9) T. Kojima, Y. Liu and J. Inoue: Trans. Jpn. Soc. Mech. Eng. B, 70 (2009), 1972 (in Japanese).

10) E. Rathakrishnan, K. Suzuki and H. Kubota: Theory of Compressible Flow, Maruzen, Tokyo, (2008), 24

11) K. Naito, Y. Ogawa, T. Inomoto, S. Kitamura and M. Yano: ISIJ Int., 40 (2000), 23. 